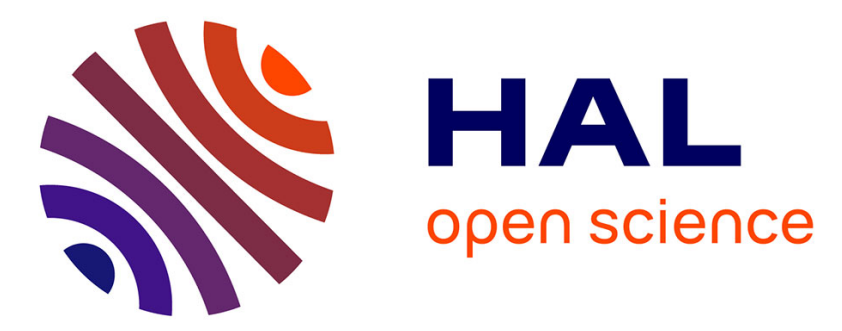

\title{
Responses of naïve and experienced European rabbits to predator odour
}

Carlos Rouco, Rafael Villafuerte, Francisca Castro, Pablo Ferreras

\section{To cite this version:}

Carlos Rouco, Rafael Villafuerte, Francisca Castro, Pablo Ferreras. Responses of naïve and experienced European rabbits to predator odour. European Journal of Wildlife Research, 2010, 57 (2), pp.395-398. 10.1007/s10344-010-0443-4 . hal-00629070

\section{HAL Id: hal-00629070 https://hal.science/hal-00629070}

Submitted on 5 Oct 2011

HAL is a multi-disciplinary open access archive for the deposit and dissemination of scientific research documents, whether they are published or not. The documents may come from teaching and research institutions in France or abroad, or from public or private research centers.
L'archive ouverte pluridisciplinaire HAL, est destinée au dépôt et à la diffusion de documents scientifiques de niveau recherche, publiés ou non, émanant des établissements d'enseignement et de recherche français ou étrangers, des laboratoires publics ou privés. 


\title{
Responses of naïve and experienced European rabbits to predator odour
}

\author{
Carlos Rouco • Rafael Villafuerte • Francisca Castro • \\ Pablo Ferreras
}

Received: 15 January 2010 /Revised: 18 June 2010 /Accepted: 19 September 2010 /Published online: 5 October 2010

(C) Springer-Verlag 2010

\begin{abstract}
The response of prey species to predator scent has been investigated in many mammalian species; however, there is little information about the responses of European wild rabbits at the population level. Therefore, we conducted a simple experiment to investigate the behavioural response of a rabbit population to native predator cues in the wild. We compared the response to the scent of a predator (red fox) in a wild rabbit population bred in semi-natural conditions and naïve to terrestrial predators with the response of a population in a similar environment where terrestrial predators were present. The response to predators was based on rabbit abundance, inferred from pellet counts and measured by the defecation rate per day (DRD). Our results indicate that rabbits responded to the odour of
\end{abstract}

Communicated by C. Gortázar

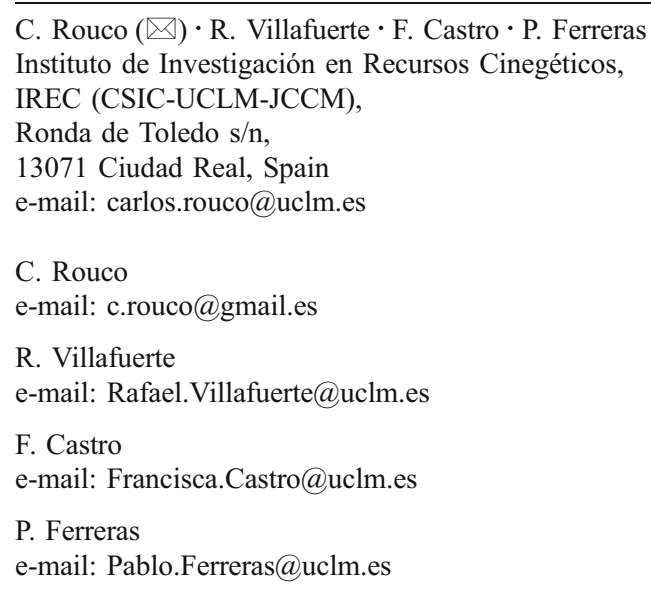

C. Rouco $(\varangle) \cdot$ R. Villafuerte $\cdot$ F. Castro $\cdot$ P. Ferreras Instituto de Investigación en Recursos Cinegéticos, IREC (CSIC-UCLM-JCCM),

Ronda de Toledo $\mathrm{s} / \mathrm{n}$,

13071 Ciudad Real, Spain

e-mail: carlos.rouco@uclm.es

C. Rouco

e-mail: c.rouco@gmail.es

R. Villafuerte

e-mail: Rafael.Villafuerte@uclm.es

F. Castro

e-mail: Francisca.Castro@uclm.es

P. Ferreras

e-mail: Pablo.Ferreras@uclm.es

fox faeces in the treatment warrens, resulting in a lower DRD. The main anti-predator behaviour observed was spatial avoidance (warren abandonment), which seemed to be more accentuated for rabbits who had not previously had contact with foxes in the plot where terrestrial predators were excluded. In both the fenced and the unfenced plot, the differences in the effect of the predator odour between the control and treatment warrens disappeared after cessation of treatment, suggesting a flexible and adaptive behaviour of rabbits to predator cues.

Keywords Artificial warren B Behaviour - Oryctolagus cuniculus $\cdot$ Pellet counts $\cdot$ Predation risk

\section{Introduction}

Predation is a central feature of ecological communities. Most studies of predator-prey interactions have focused on the capture or consumption of prey by predators; however, predator effects on prey are not limited to predation because it is known that a prey can respond to predators by altering phenotypic traits to reduce the risk of mortality (Preisser et al. 2005). Prey responses do not require the presence of predators, they can be induced by cues of their presence, for instance their scent. Many types of responses to predator scent have been investigated among prey species. Spatial avoidance and changes in foraging behaviour have been observed in rodents when a predator cue or scent is present (Wolff and Davis-Born 1997; Ylönen et al. 2006).

Several studies have investigated the responses of European wild rabbit (Oryctolagus cuniculus) to predators. 
Most of these experiments have used individuals under laboratory conditions, and few attempts have been made to validate the results under field conditions (Apfelbach et al. 2005; Monclús et al. 2006). For example, in a laboratory experiment, Monclús et al. (2005) demonstrated that wild rabbits recognise predator odours, independently of prior experience; however, the response to fox odour under seminatural conditions was not as pronounced as under laboratory conditions (Monclús et al. 2006). In another experiment under natural conditions, the grazing spatial behaviour of rabbits was not affected by manipulation of predation risk, but it influenced rabbit temporal activity pattern (Bakker et al. 2005); however, there is little information about the behavioural responses of rabbits at the population level in the wild.

Thus, we conducted a simple experiment to investigate the effect of previous experience on the response of a rabbit population to native predator cues in the wild. We expected that both rabbit populations, one experienced and another naïve to terrestrial predators, will respond to the scent of a predator (red fox, Vulpes vulpes) (Monclús et al. 2006; Vitale 1989).

\section{Materials and methods}

Study area and the origin of the animals

The experiment was conducted in two plots (4 ha each, see Rouco et al. 2008) separated by $1 \mathrm{~km}$ in Sierra Norte Natural Park of Seville (SW Spain). Eighteen artificial warrens were regularly distributed on each plot and separated 35-40 m (see Rouco et al. 2010b for further information). Water and food suppliers located close to each warren provided rabbits with water and commercial food pellets ad libitum. One of the plots was surrounded by a fence $3 \mathrm{~m}$ high that was topped with an electric shepherd to completely exclude terrestrial predators. Rabbits in this plot were mostly descendants of wild individuals that were translocated during autumn 2002 (Rouco et al. 2010a); thus they were therefore largely naïve to direct contact with any terrestrial predator. The second plot was unfenced, so rabbits were in contact with terrestrial predators. Red fox is the main predator in this area (average density 0.79 foxes $/ \mathrm{km}^{2}$, authors unpublished).

Sampling design

As a source of odour, we used fresh red fox faeces collected in the study area. To make the odour uniform throughout the experiment, $500 \mathrm{~g}$ of faeces were stirred with $2 \mathrm{~L}$ of water, and the mixture was left standing for $72 \mathrm{~h}$. The resulting solution (henceforth referred to as fox faeces odour) was filtered and frozen at $-20^{\circ} \mathrm{C}$ until used.
In each plot, three treatment and three control warrens were randomly selected, and two odour stations were added to each warren; each station consisted of a chalk tied at approximately $20 \mathrm{~cm}$ above ground to a sheaf nailed in the ground. In the treatment warrens, the chalks were impregnated with $4 \mathrm{ml}$ of fox faeces odour every 3 days during the treatment period (March to August 2004). Odour stations in the control warrens were impregnated with water following the same regime as for the treatment warrens.

To evaluate the presence of predators, and thus the predation risk perceived by the animals in the unfenced plot, counts of scats were performed weekly on an $800-\mathrm{m}$ walk transect within the plot.

The monitoring of rabbit abundances and trends during the experiment was based on pellet counts (Rouco et al. 2008). Pellets were counted and cleared from ten fixed circular plots $(18 \mathrm{~cm}$ in diameter) placed randomly at $5 \mathrm{~m}$ far for each warren. Pellet counts were performed four times during the study period; first count in February 2004 (before treatment); second and third counts during May and August, respectively (during treatment) and last count in November (after treatment). To standardise all pellet counts, a defecation rate per day (DRD) was calculated for each count. The DRD was obtained by dividing the number of pellets at each counting station by the number of days since the last count at the same station (Cabezas and Moreno 2007).

\section{Data analysis}

Pellet abundance data were analyzed using generalized linear mixed models, as implemented in SAS (SAS Institute, Inc. 2004; Genmod, Glimmix and mixed procedures) with 'warren' and 'pellet counting station' as random categorical variables. The dependent variable DRD was modelled with Poisson errors and log link. Three factors were considered in the models of pellet abundance: 'treatment' (control and treatment warrens), 'plot' (fenced and unfenced) and 'counts' (each pellet count in February, May, August and November). Denominator degrees of freedom were estimated using Satterthwaite's formula (Littell et al. 1996). Nonparametric tests were used to check for differences in pellet abundance between the control and treatment warrens.

\section{Results}

No differences were found in rabbit pellet abundance between the control and treatment warrens before the treatment in either the unfenced (Mann-Whitney $U$ test, before: $Z=0.28$, $p=0.779$ ) or the fenced plot (Mann-Whitney $U$ test, before: $\mathrm{Z}=0.63, p=0.294)$. Rabbit population trends in both plots 
(unfenced and fenced) were similar (Fig. 1) and no significant differences were found in the DRD between the two plots during the study period (Table 1; plot $\times$ count). We found a significant effect of treatment (Table 1) with higher DRD in the control than in the treatment warrens in both plots (Fig. 1). The DRD value in control warrens at the end of the experiment was 4.6 times higher in the fenced than the unfenced plot (Mann-Whitney $U$ test, $\mathrm{Z}=-3.386, p<0.001$ ); however, after cessation of treatment, the DRD was not different between the control and treatment warrens in the unfenced (Mann-Whitney $U$ test: $Z=0.15, p=0.144$ ) and the fenced plots $(Z=-0.59, p=0.554)$. Predator activity in the unfenced plot increased more than fourfold during the study, as indicated by the predator scats collected along the walk transects (three in February, four in May, 18 in August and 23 in November).

\section{Discussion}

Consistent with previous studies (Monclús et al. 2005; Vitale 1989), our results indicate that rabbits respond to fox

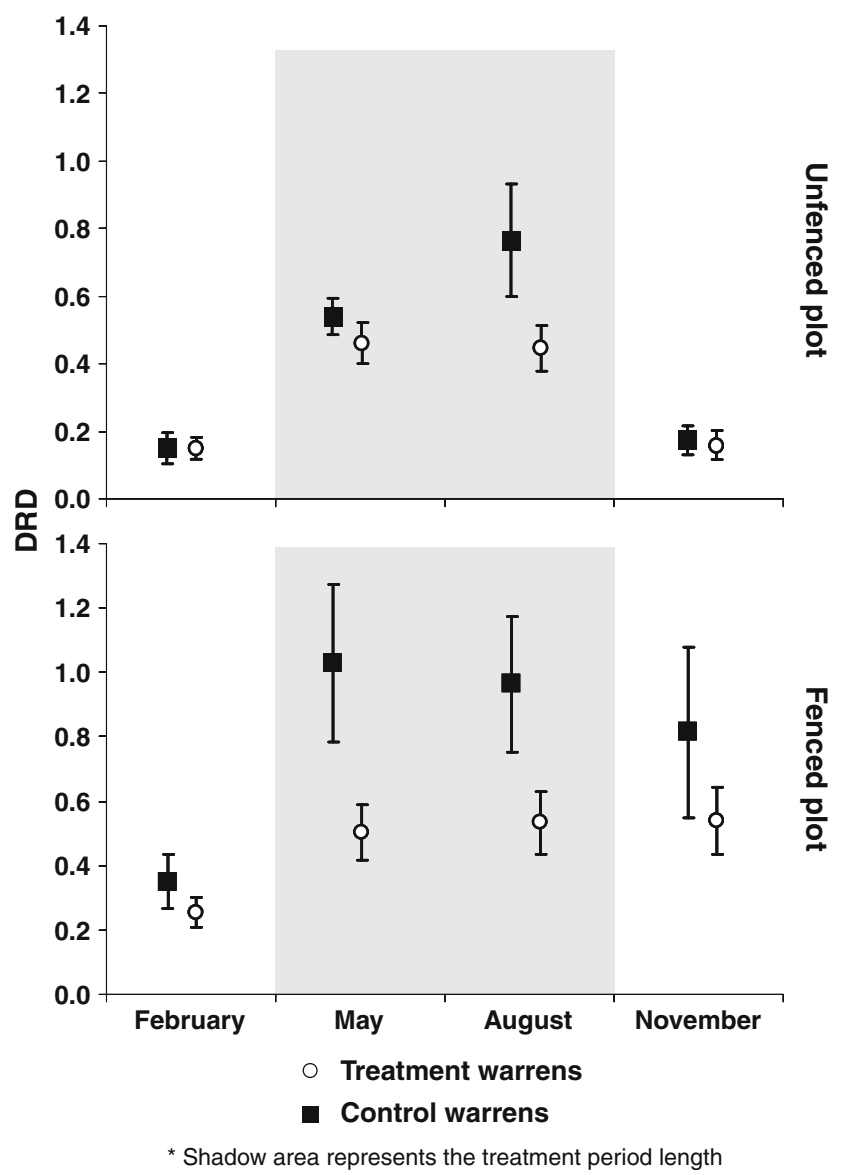

Fig. 1 Comparison of DRD (rabbit defecation rate per day) during the four pellet counts (means \pm standard error) on control and treatment warrens in unfenced and fenced plot
Table $1 F$ values in generalized linear mixed models of the effect of treatment (control warrens vs. treatment warrens), plot (unfenced vs. fenced) and pellet counts (counts)

\begin{tabular}{llrl}
\hline Predictors & DF & \multicolumn{1}{l}{$F$} & $P$ \\
\hline Treatment & 1,358 & 7.05 & 0.008 \\
Plot & 1,358 & 10.80 & 0.001 \\
Counts & 1,358 & 4.85 & 0.028 \\
plot $\times$ count & 1,357 & 0.43 & 0.514 \\
plot $\times$ treatment & 1,357 & 1.29 & 0.257 \\
plot $\times$ count $\times$ treatment & 1,355 & 0.15 & 0.696 \\
\hline
\end{tabular}

odour, even those rabbits naïve to predator cues. The main anti-predator behaviour observed was spatial avoidance, as evidenced by the lower DRD in the treatment warrens. Some animals may have left the treatment warrens due to a greater perceived predation risk. In fact, the effect of intimidation by predators seems to be more important than the consumption of prey during predator-prey interactions (Preisser et al. 2005). The reduced response in the plot with experienced animals (unfenced plot) could be explained by the fact that the control warrens were not an ideal control because predator scats were naturally occurring nearby. This is not unexpected because fox scent marks were more common in areas of higher rabbit density (Monclús et al. 2009). Thus, the natural presence of odour in both treatment and control warrens in the unfenced plot could reduce the effect of the treatment. For instance, Monclús et al. (2005) suggested that under natural conditions, such as it occurs in our unfenced plot, rabbits can change their use of space in the presence of predator cues. Several studies have confirmed a response of mammalian prey to novel olfactory cues per se, but the response is generally stronger with predator scent marks than with non-predator odours (Bakker et al. 2005; Bramley et al. 2000).

In the plot with the predator exclusion fence, the effect of the treatment was apparently greater at the beginning of the experiment (Fig. 1). After the initial stage, the differences in DRD between the control and treatment warrens decreased. Learnt behaviour could be modulating this response (Griffin et al. 2000), but this was less likely in the unfenced plot owing to the continuous presence of terrestrial predators.

Finally, in both the fenced and unfenced plots, we observed that the effect of the predator odour between the control and treatment warrens apparently disappeared following cessation of the treatment. Bakker et al. (2005) also manipulated perceived predation risks of a population of rabbits using predator odour and showed temporal avoidance of predation. It may be that after the treatment ceased and predator cues could no longer be detected, rabbits began re-occupying the warrens, suggesting the 
involvement of a flexible and adaptive response to predator cues.

Acknowledgements C. Rouco was supported by a postdoctoral grant from the regional government of Castilla-La Mancha and the European Social Fund. Funding was provided by the projects by Confederación Hidrográfica del Guadalquivir, by the Projects CGL2009-10741, CGL2009-11665, FAU2006-0014-C-02-02, POII09-0099-2557 and PEII09-0097-436. Special thanks go to G. Calabuig, J. Castillo, A. Finque, C. Iriarte, A. Linares, S. Luna, L. E. Mínguez, O. Rodriguez and M. Reglero for their support during field work. J. Blanco-Aguilar and D. Canal provided statistical assistance, and finally thanks to M. Delibes-Mateos and one anonymous referee for their helpful comments on previous drafts of the manuscript.

\section{References}

Apfelbach R, Blanchard CD, Blanchard RJ, Hayes RA, McGregor IS (2005) The effect of predator odours in mammalian prey species: a review of field and laboratory studies. Neurosci Biobehav Rev 29:1123-1144

Bakker ES, Reiffers RC, Olff H, Gleichman JM (2005) Experimental manipulation of predation risk and food quality: effect on grazing behaviour in a central-place foraging herbivore. Oecologia 146:157167

Bramley GN, Waas JR, Henderson HV (2000) Responses of wild Norway rats (Rattus norvegicus) to predator odours. J Chem Ecol 26:705-719

Cabezas S, Moreno S (2007) An experimental study of translocation success and habitat improvement in wild rabbits. Anim Conserv 10:340-348

Griffin AS, Blumstein DT, Evans CS (2000) Training captive-bred or translocated animals to avoid predators. Conserv Biol 14:1317-1326
Littell RC, Milliken GA, Stroup WW, Wolfinger RD (1996) SAS system for mixed models. SAS Inst. Inc., Cary

Monclús R, Rödel GH, von Holst D, de Miguel FJ (2005) Behavioural and physiology responses of naïve European rabbits to predator odour. Anim Behav 70:53-761

Monclús R, von Rödel HG, Holst D (2006) Fox odour increases vigilance in european rabbits: a study under semi-natural conditions. Ethology 112:1186-1193

Monclús R, Arroyo M, Valencia A, de Miguel FJ (2009) Red foxes (Vulpes vulpes) use rabbit (Oryctolagus cuniculus) scent marks as territorial marking sites. J Ethol 27:153-156

Preisser EL, Bolnick DI, Benard MF (2005) Scared to death? The effects of intimidation and consumption in predator-prey interactions. Ecology 86:501-509

Rouco C, Ferreras P, Castro F, Villafuerte R (2008) The effect of exclusion of terrestrial predators on short-term survival of translocated European wild rabbits. Wildl Res 35:625-632

Rouco C, Ferreras P, Castro F, Villafuerte R (2010a) A longer confinement period favors European wild rabbit (Oryctolagus cuniculus) survival during soft releases in low-cover habitats. Eur J Wildl Res 56:215-219

Rouco C, Villafuerte R, Castro F, Ferreras P (2010b) Effect of artificial warren size on a restocked European wild rabbit population. Anim Conserv (in press)

SAS Institute, Inc. (2004) SAS/STAT 91 User's Guide. SAS Publishing, Cary

Vitale AF (1989) Changes in the anti-predator responses of wild rabbits, Oryctolagus cuniculus, (L), with age and experience. Behaviour 110:47-68

Wolff JO, Davis-Born D (1997) Response of gray-tailed voles to odours of a mustelid predator: a field test. Oikos 79:543548

Ylönen H, Eccard JA, Jokinen I, Sundell J (2006) Is the antipredatory response in behaviour reflected in stress measured in faecal corticosteroids in a small rodent? Behav Ecol Sociobiol 60:350 358 